\title{
Visualisation of time-varying respiratory system elastance in experimental ARDS animal models
}

\author{
Erwin J van Drunen ${ }^{1}$, Yeong Shiong Chiew ${ }^{1}$, Christopher Pretty ${ }^{1}$, Geoffrey M Shaw ${ }^{3}$, Bernard Lambermont ${ }^{4}$, \\ Nathalie Janssen ${ }^{4}$, J Geoffrey Chase ${ }^{1}$ and Thomas Desaive 2 $^{2^{*}}$
}

\begin{abstract}
Background: Patients with acute respiratory distress syndrome (ARDS) risk lung collapse, severely altering the breath-to-breath respiratory mechanics. Model-based estimation of respiratory mechanics characterising patient-specific condition and response to treatment may be used to guide mechanical ventilation (MV). This study presents a model-based approach to monitor time-varying patient-ventilator interaction to guide positive end expiratory pressure (PEEP) selection.

Methods: The single compartment lung model was extended to monitor dynamic time-varying respiratory system elastance, $E_{d r s}$ within each breathing cycle. Two separate animal models were considered, each consisting of three fully sedated pure pietrain piglets (oleic acid ARDS and lavage ARDS). A staircase recruitment manoeuvre was performed on all six subjects after ARDS was induced. The $E_{\text {drs }}$ was mapped across each breathing cycle for each subject.

Results: Six time-varying, breath-specific $E_{d r s}$ maps were generated, one for each subject. Each $E_{d r s}$ map shows the subject-specific response to mechanical ventilation (MV), indicating the need for a model-based approach to guide MV. This method of visualisation provides high resolution insight into the time-varying respiratory mechanics to aid clinical decision making. Using the $E_{d r s}$ maps, minimal time-varying elastance was identified, which can be used to select optimal PEEP.

Conclusions: Real-time continuous monitoring of in-breath mechanics provides further insight into lung physiology. Therefore, there is potential for this new monitoring method to aid clinicians in guiding MV treatment. These are the first such maps generated and they thus show unique results in high resolution. The model is limited to a constant respiratory resistance throughout inspiration which may not be valid in some cases. However, trends match clinical expectation and the results highlight both the subject-specificity of the model, as well as significant inter-subject variability.
\end{abstract}

Keywords: Mechanical ventilation, PEEP, Time-varying elastance, Model-based methods, ARDS, Monitoring

\section{Background}

Acute respiratory distress syndrome (ARDS) [1] results in a stiffer lung [2]. ARDS patients are admitted to the intensive care unit (ICU) and require mechanical ventilation (MV) for breathing support. Positive end expiratory pressure (PEEP) is applied to aid recovery by improving gas exchange and maintaining recruited lung volume [3-6]. However, variation in a patient's response to MV and the heterogeneity of ARDS means there is a need to determine optimal patient-specific PEEP [3,7].

\footnotetext{
* Correspondence: tdesaive@ulg.ac.be

¿2University of Liège, Liège, Belgium

Full list of author information is available at the end of the article
}

ARDS involves alterations in a patient's breath-to-breath respiratory mechanics. Modelling these alterations can potentially provide a non-invasive, patient-specific method to obtain clinically and physiologically useful information to guide treatment in real-time [8-11]. This approach can provide unique insight into disease progression and patient response to MV [12-15]. However, real-time monitoring of respiratory mechanics throughout MV treatment is, to date, limited in clinical application and impact [16].

Dynamic respiratory system elastance $\left(E_{d r s}\right)$ is a breath-specific time-varying lung elastance [17]. Dynamic elastance within a breath provides unique insight into a
Ciomed Central

(c) 2014 van Drunen et al.; licensee BioMed Central Ltd. This is an Open Access article distributed under the terms of the Creative Commons Attribution License (http://creativecommons.org/licenses/by/2.0), which permits unrestricted use, distribution, and reproduction in any medium, provided the original work is properly credited. 
patient's breathing pattern, revealing lung recruitment and overdistension $[17,18]$. In addition, identifying when minimum $E_{d r s}$ (maximum compliance) occurs during PEEP titration can help identify an optimal patientspecific PEEP to minimise work of breathing (WOB) and maximise recruitment without inducing further lung injury $[19,20]$. This work presents a novel method of visualising the time-varying respiratory elastance to provide a higher resolution metric to guide MV therapy.

\section{Methods}

\section{Dynamic respiratory system elastance model}

The equation of motion describing the airway pressure as a function of the resistive and elastic components of the respiratory system is defined as [21]:

$$
P_{a w}(t)=R_{r s} \times Q(t)+E_{r s} \times V(t)+P_{0}
$$

where $P_{a w}$ is the airway pressure, $t$ is time, $R_{r s}$ is the series resistance of the conducting airway, $Q$ is the air flow, $E_{r s}$ is an overall respiratory system elastance (1/compliance), $V$ is the lung volume and $P_{O}$ is the offset pressure.

During inspiration, a fully sedated patient will have a near constant chest wall elastance, $E_{c w}$. Thus, changes in the respiratory system elastance, $E_{r s}$, are attributed directly to the patient's lung elastance, $E_{\text {lung, }}$, as shown in Equation 2, thereby providing insight into patient condition and ARDS severity $[2,21]$.

$$
E_{r s}=E_{c w}+E_{\text {lung }}
$$

Equation 3 describes an integral-based method [22] used to estimate values of $E_{r s}$ and $R_{r s}$ that best fit Equation 1 . Integral-based parameter identification is similar to multiple linear regression, where using integrals significantly increases robustness to noise $[17,22]$.

$$
\int P_{a w}(t) d t=R_{r S I B} \times \int Q(t) d t+E_{r s I B} \times \int V(t) d t+\int P_{0} d t
$$

Respiratory resistance is assumed constant throughout a breath [17], but can vary with PEEP and time due to opening or closing of respiratory system airways [12,14,17,23]. Thus, once $R_{r s}$ is determined for a particular breath using Equation 3, it is substituted into Equation 4 where dynamic lung elastance, $E_{d r s}$, is defined as a time-varying lung elastance, such that $E_{r s}$ is effectively the average of $E_{d r s}$.

$$
P_{a w}(t)=R_{r s} \times Q(t)+E_{d r s}(t) \times V(t)+P_{0}
$$

Thus, $E_{d r s}$ can be determined from:

$$
E_{d r s}(t)=\frac{P_{a w}(t)-P_{0}-R_{r s} \times Q(t)}{V(t)}
$$

In this way, significantly more insight is gained into the respiratory elastance over the course of inspiration than can be provided by a single value of $E_{r s}$.

During a PEEP increase, recruitment of new lung volume outweighs lung stretching provided that the global measure of $E_{d r s}$ decreases breath-to-breath [17]. Hence, the dynamic trajectory of $E_{d r s}$ captures the overall balance of volume (recruitment) and pressure (risk) within the lung.

\section{Experimental data}

Two experimental ARDS animal models are considered, each using three fully sedated pure pietrain piglets. The criterion for ARDS is limited to hypoxemia monitoring where the $\mathrm{PaO}_{2} / \mathrm{FiO}_{2}$ (PF ratio) is less than $300 \mathrm{mmHg}$.

1. Oleic Acid ARDS Models [24]: Each subject (Subjects 1-3) was sedated and ventilated through a tracheotomy under volume control (tidal volume, $V_{t}=8-10 \mathrm{ml} / \mathrm{kg}$ ) with an inspired oxygen fraction $\left(\mathrm{FiO}_{2}\right)$ of 0.5 and a respiratory rate of 20 breaths $/ \mathrm{min}$ using an Engström CareStation ventilator (Datex, General Electric, Finland). ARDS was induced using oleic acid [25] and the arterial blood gas (ABG) was monitored half hourly. Once diagnosed with ARDS, each subject underwent a staircase recruitment manoeuvre (RM) with a PEEP level sequence of $5-10-15-20-15-10-$ $5 \mathrm{cmH}_{2} \mathrm{O}$ [26]. Breathing was maintained for approximately $10-15$ breathing cycles at each PEEP level. Airway pressure and flow data were acquired using the Eview module provided with the ventilator. The data sampling rate was $25 \mathrm{~Hz}$.

2. Lavage ARDS Models: After sedation and intubation via tracheotomy, the piglets (Subjects 4-6) were ventilated by intermittent positive pressure ventilation mode using a Drager Evita2 ventilator (Drager, Lubeck Germany). The ventilator was set to deliver a tidal volume of $8-10 \mathrm{ml} / \mathrm{kg}$ with a $\mathrm{FiO}_{2}$ of 0.5 at a respiratory rate of 20 breaths $/ \mathrm{min}$. Each subject underwent surfactant depletion using lavage methods [25]. The ABG was monitored and once diagnosed with ARDS, each subject underwent a staircase RM with PEEP settings at $1-5-10-15$ $20-15-10-5-1$ mbar [26]. Breathing was maintained for approximately 10-15 breathing cycles at each PEEP level. Airway pressure and flow were measured using a 4700B pneumotachometer (Hans Rudolph Inc., Shawnee, KS) at a sampling rate of $200 \mathrm{~Hz}$. Calibration was performed by matching pressure flow curve from the pneumotachometer to the peak inspiratory pressure (PIP), positive end expiratory pressure (PEEP), flow displayed in Drager Evita2 ventilator (Drager, Lubeck, Germany). 
Airway pressure and flow rate data was analysed using MATLAB (The Mathworks, Natick, Massachusetts, USA). All experimental procedures, protocols and the use of data in this study were reviewed and approved by the Ethics Committee of the University of Liege Medical Faculty.

\section{Visualisation of the dynamics (Elastance)}

Dynamic respiratory system elastance $\left(E_{d r s}\right)$ varies within a breath as recruitment or overdistension occurs. Similarly, $E_{d r s}$ will evolve with time as recruitment is time dependent $[27,28]$, disease state dependent $[6,29]$ and MV dependent $[28,30]$. Arranging each breathing cycle's $E_{d r s}$ curve such that it is bounded by the $E_{d r s}$ curve of the preceding breath and the subsequent breath leads to a three-dimensional, time-varying, breath-specific $E_{d r s}$ map. This method of visualisation gives new insight into how the breath-to-breath respiratory mechanics change with time over the course of treatment. In a similar manner, the corresponding change in airway pressure from PEEP to peak inspiratory pressure (PIP) is also displayed for each subject.

The dynamic elastance for each breath is calculated by dividing the numerator of Equation 5 by the volume vector. Therefore, at the very start of inspiration, when inspired volume is very small, $E_{d r s}$ approaches physiologically unrealistic values. Since overdistension is unlikely to occur at low volumes, the initial $20 \%$ of the inspiratory time for each breath is neglected for clarity. During this time, volume increases by approximately 0.04-0.06 L (less than $20 \%$ of the total inspired tidal volume) for each subject.

\section{Results}

Each subject has approximately 160 to 360 breathing cycles over the course of the RM. All breathing cycles are normalised to their total inspiratory time to provide clarity and to ensure consistency between breaths with different inspiratory times. Thus, each breath effectively begins at $0 \%$ and ends at $100 \%$ of the total inspiration time. The time-varying, breath-specific $E_{d r s}$ map of the RM for Subjects 1-6 are shown in Figures 1, 2, 3, 4, 5 and 6 respectively, where blue indicates low $E_{d r s}$ and red indicates high $E_{d r s}$. The corresponding airway pressure and PEEP are shown in grey. The PF ratio for each subject is stated in the corresponding figure caption. Each figure is also provided with a MATLAB figure in a compressed zip file to permit rotation. The $E_{d r s}$ and $R_{r s}$ for each subject over the course of the RM is also shown within each MATLAB figure file (see Additional file 1). The top view of all $E_{d r s}$ maps are shown in Additional file 2.

\section{Discussion}

\section{General observations}

All subjects showed, to some degree, an increase in $E_{d r s}$ immediately following a PEEP step increase of $5 \mathrm{cmH}_{2} \mathrm{O}$

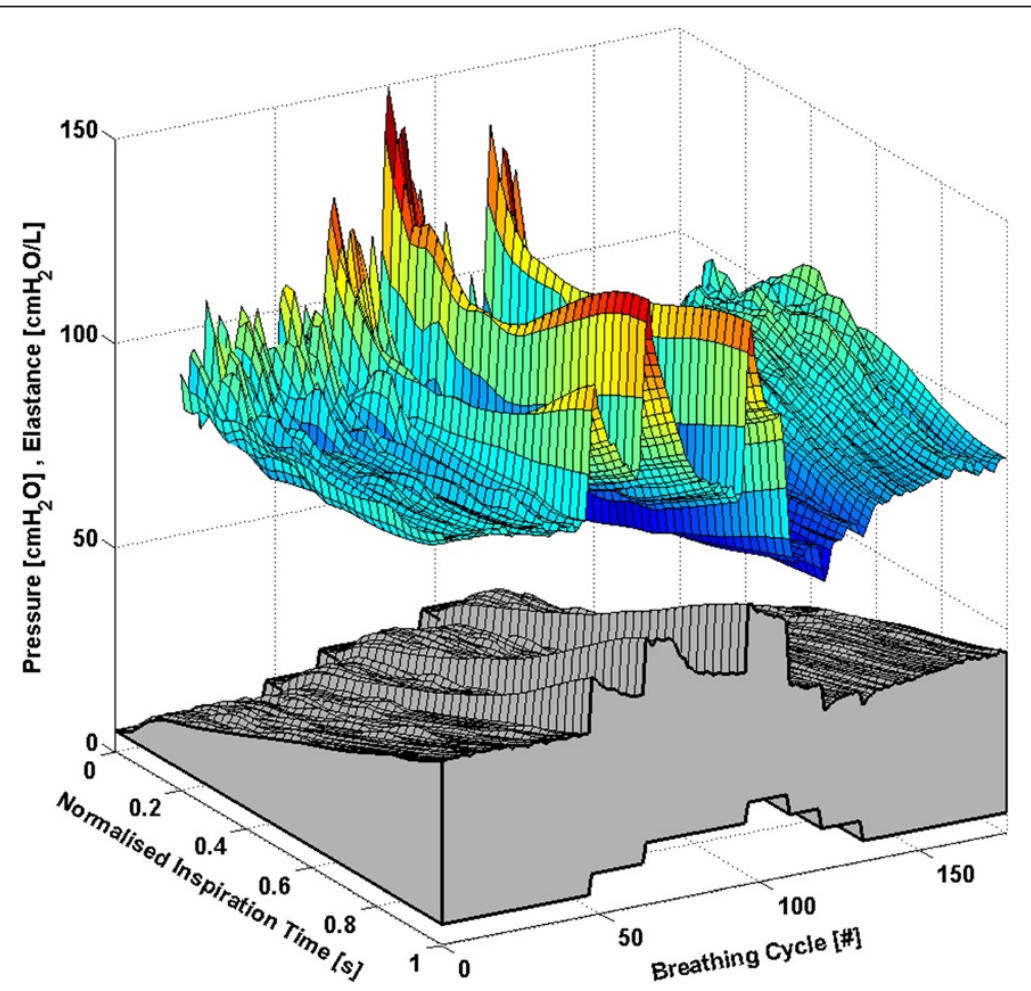

Figure 1 Variation in $E_{d r s}$ across a normalised breath during a RM for Subject $1\left(\mathrm{PaO}_{2} / \mathrm{FiO}_{2}=126.6 \mathrm{mmHg}\right)$. The change in airway pressure for each normalised breathing cycle is shown in grey. 


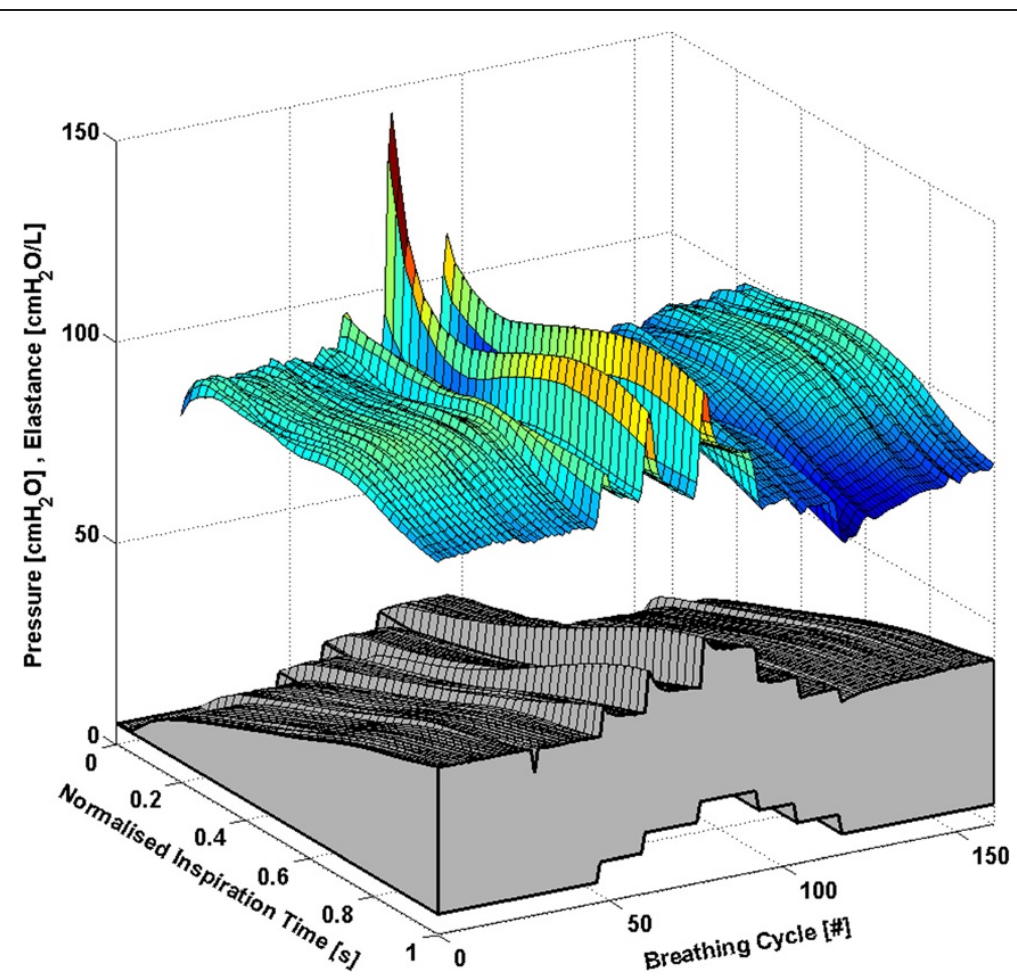

Figure 2 Variation in $E_{d r s}$ across a normalised breath during a $\mathrm{RM}$ for Subject $2\left(\mathrm{PaO}_{2} / \mathrm{FiO}_{2}=183.6 \mathrm{mmHg}\right)$. The change in airway pressure for each normalised breathing cycle is shown in grey.

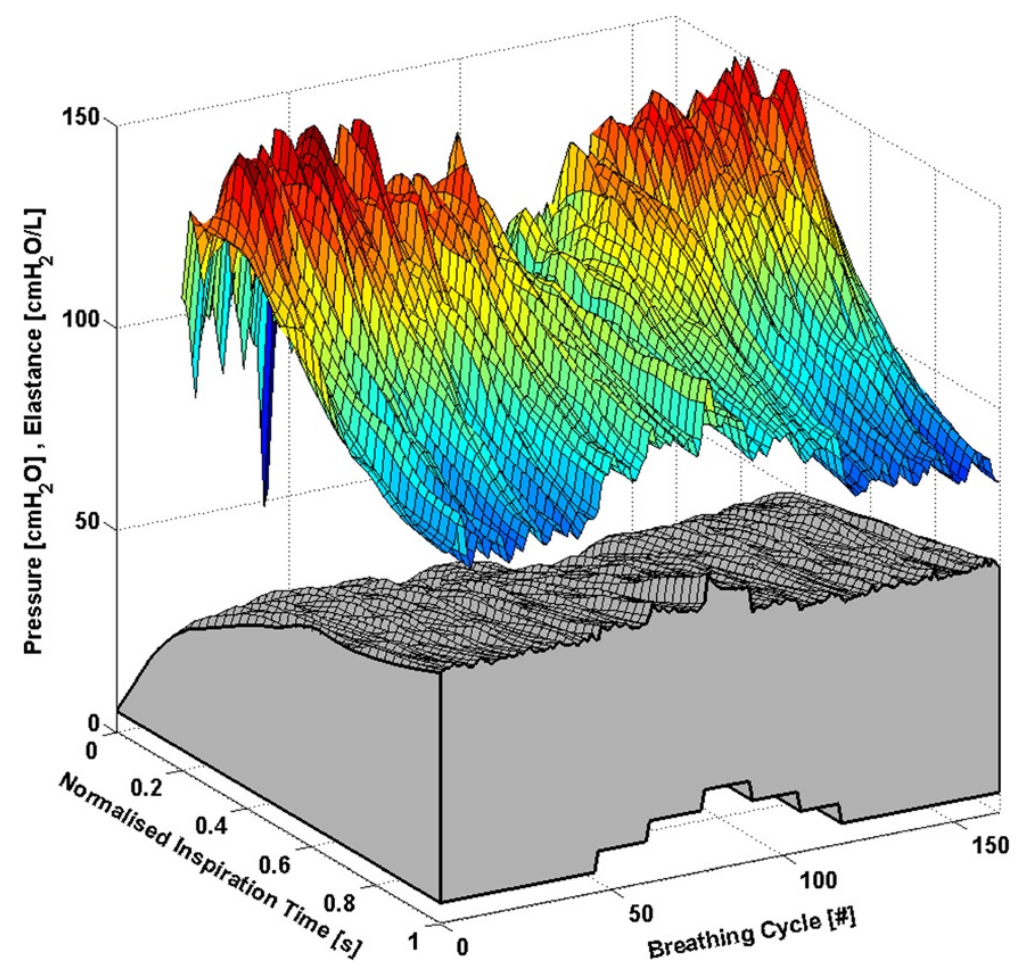

Figure 3 Variation in $E_{d r s}$ across a normalised breath during a RM for Subject $3\left(\mathrm{PaO}_{2} / \mathrm{FiO}_{2}=113.6 \mathrm{mmHg}\right)$. The change in airway pressure for each normalised breathing cycle is shown in grey. 


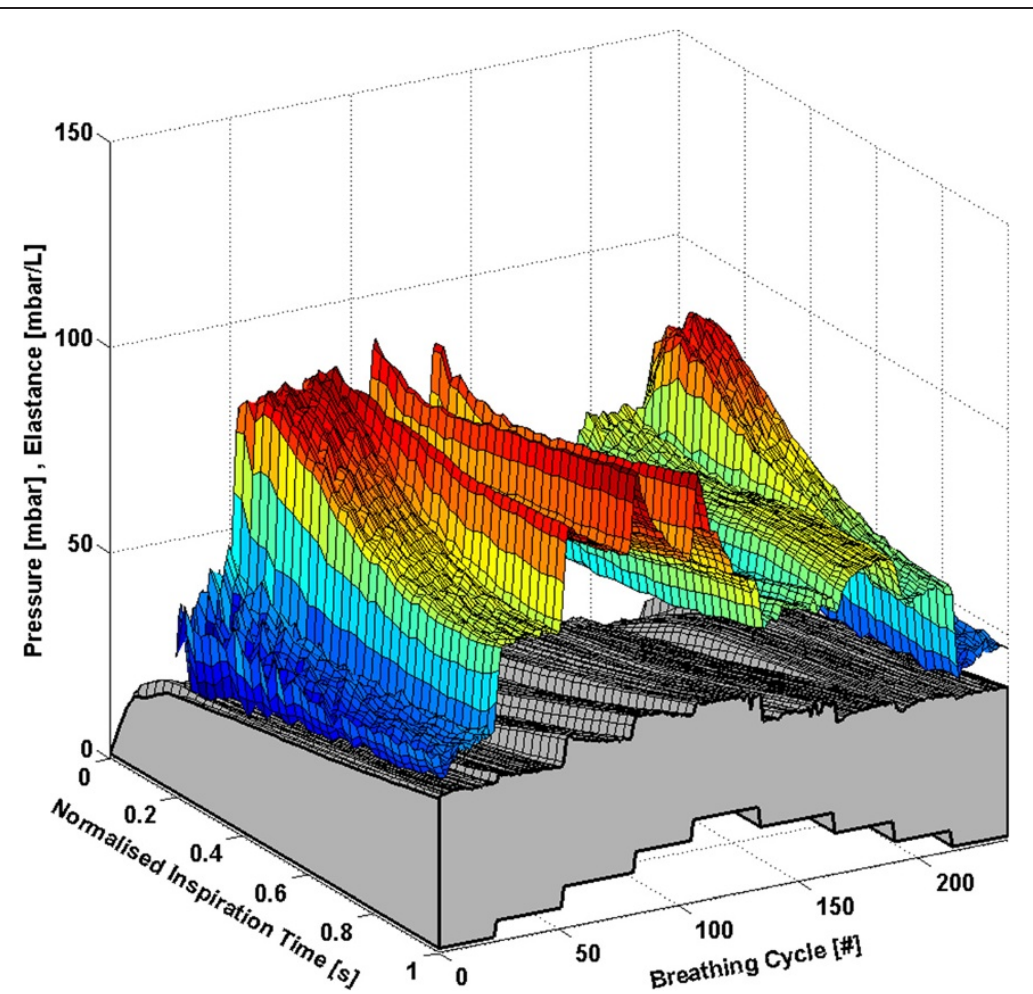

Figure 4 Variation in $E_{d r s}$ across a normalised breath during a $\mathrm{RM}$ for Subject $4\left(\mathrm{PaO}_{2} / \mathrm{FiO}_{2}=155.2 \mathrm{mmHg}\right)$. The change in airway pressure for each normalised breathing cycle is shown in grey.

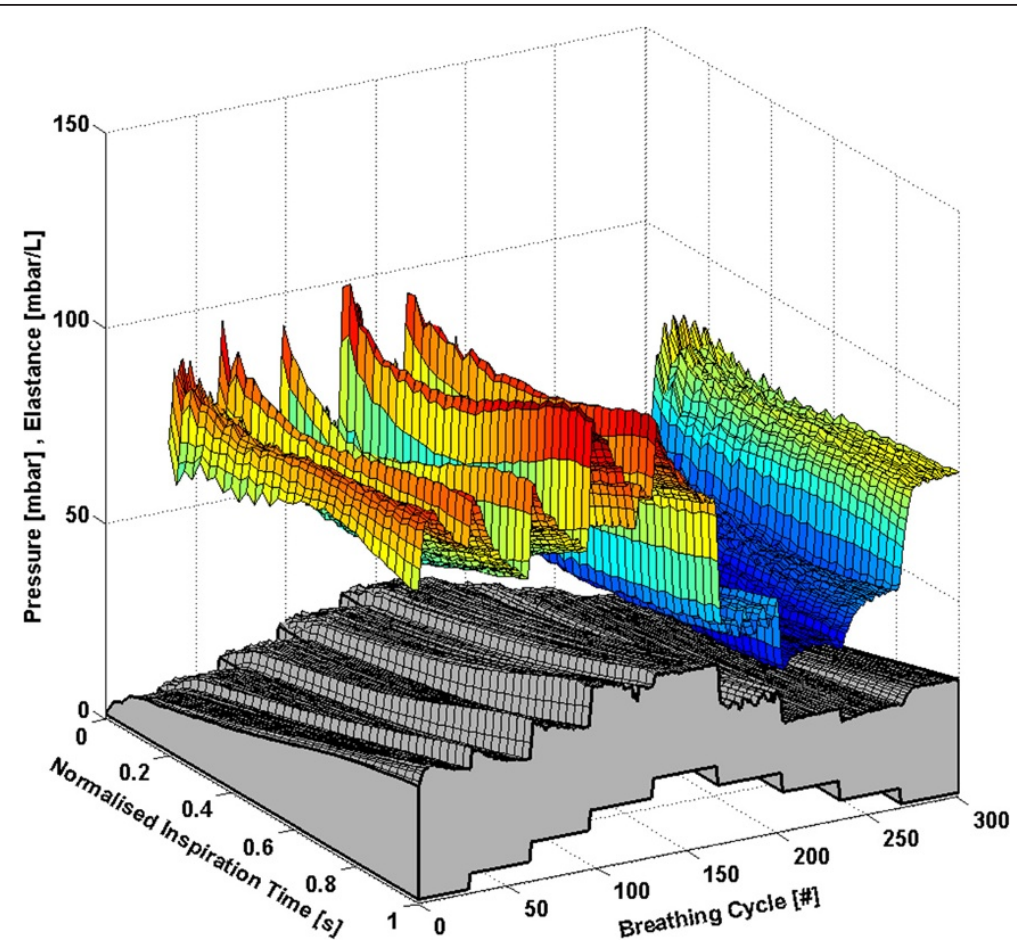

Figure 5 Variation in $E_{d r s}$ across a normalised breath during a RM for Subject $\mathbf{5}\left(\mathrm{PaO}_{2} / \mathrm{FiO}_{2}=85.9 \mathrm{mmHg}\right)$. The change in airway pressure for each normalised breathing cycle is shown in grey. 


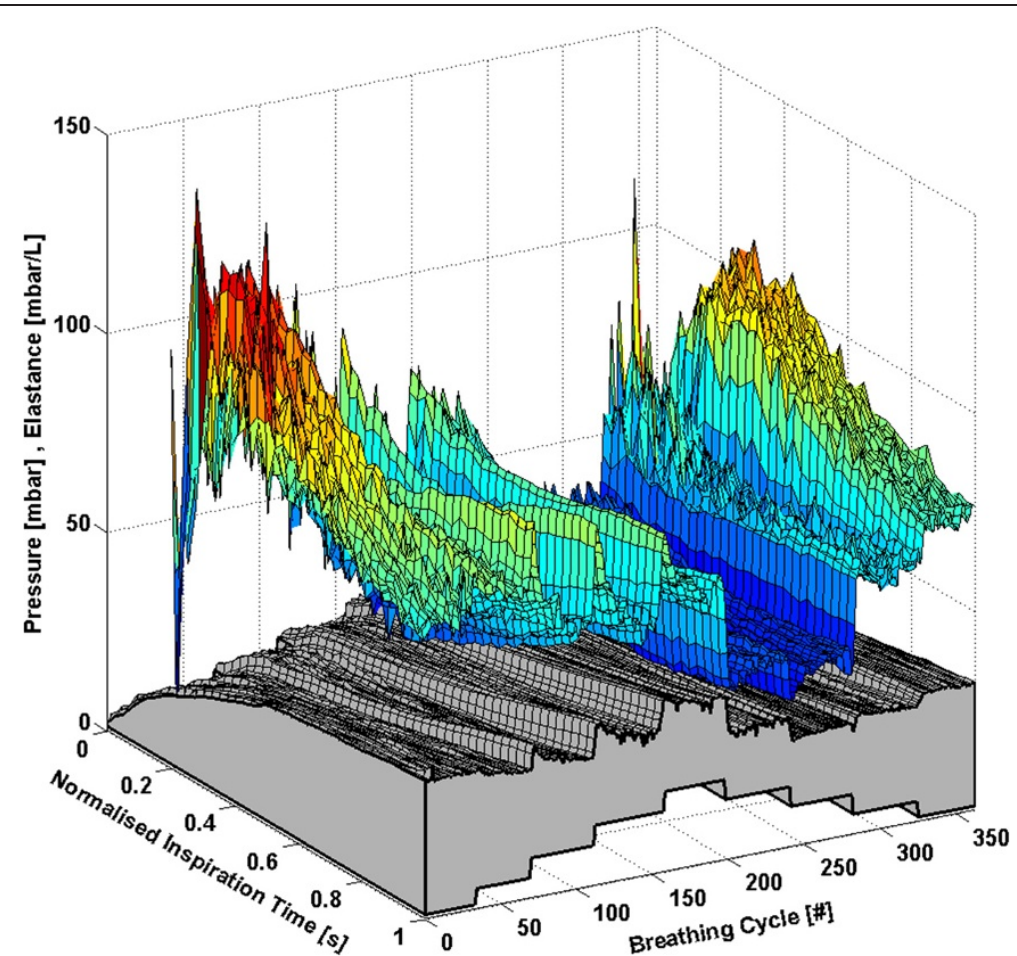

Figure 6 Variation in $E_{d r s}$ across a normalised breath during a RM for Subject $6\left(\mathrm{PaO}_{2} / \mathrm{FiO}_{2}=110.4 \mathrm{mmHg}\right)$. The change in airway pressure for each normalised breathing cycle is shown in grey.

or 5 mbar. Each successive breath had a reduced peak $E_{d r s}$ indicating the time-dependent nature of recruitment and/or the lung's viscoelastic properties, which cause hysteresis $[31,32]$. More specifically, there is a period of adaptation following an increase in PEEP that sees higher average $E_{d r s}$, peak $E_{d r s}$ and PIP before the beneficial effect of lower $E_{d r s}$ is seen. Furthermore, the $E_{d r s}$ trajectory within a breath generally decreases during inspiration, suggesting in-breath recruitment. However, directly following a PEEP step increase, some subjects show a decreasing $E_{d r s}$ trajectory, followed by an increasing $E_{d r s}$ trajectory towards the end of inspiration. High elastance indicates serious potential for lung damage due to overstretching, and may not be captured by a single value of $E_{r s}[17,18]$. Thus, as a result of this study, PEEP increments during a RM might be reduced to $1 \mathrm{cmH}_{2} \mathrm{O}$ or 1 mbar, rather than increments of $5 \mathrm{cmH}_{2} \mathrm{O}$ or $5 \mathrm{mbar}$, to avoid any damage due to the raised elastance in the early breaths and adaptation period following a PEEP increase. During a RM, smaller PEEP increments, each followed by a short period of stabilisation, may substantially reduce the peak of the $E_{d r s}$ spikes at the end of inspiration. However, it is important to note that the occurrence of lower respiratory elastance after stabilisation may also be a direct consequence of the initial high overdistension immediately following an increase in PEEP. This finding warrants further investigation where staircase recruitment is performed using smaller PEEP increments. Changes in ventilator pattern or mode to modify the $E_{d r s}$ trajectory also have potential to guide therapy.

The $E_{d r s}$ trend is significantly different between increasing and decreasing PEEP (using a non-parametric Wilcoxon rank sum test, $\mathrm{p}<0.05$ for each subject) where decreasing PEEP titration generally results in lower overall $E_{d r s}$. When PEEP increases, recruitment, as well as potential lung overstretching occurs. However, as PEEP is reduced, the lung remains compliant and $E_{d r s}$ drops to an overall minimum. Equally, this phenomenon is seen where the opening pressure of collapsed alveoli is higher than the closing pressure [29,33]. Considering increasing and decreasing PEEP separately, a local $E_{d r s}$ minimum generally occurs at the same PEEP level, suggesting that optimum PEEP can be selected either way. Recruitment is a function of PEEP and time $[28,30]$, and, equally, the ARDS affected lung is prone to collapse due to the instability of affected lung units $[6,29]$. Assuming that the severity of ARDS does not change within a short period, respiratory elastance during increasing PEEP titration is expected to reduce as time progresses to achieve stability. In contrast, respiratory elastance will increase with time during decreased PEEP to achieve stability. Hence, the authors hypothesise that PEEP can be titrated to a minimum elastance either way, provided a stabilisation 
period is given at each PEEP level to obtain a true minimal elastance.

The time-varying $E_{d r s}$ map is a higher resolution metric of dynamic adaptation to PEEP than a single $E_{r s}$ value. Selecting PEEP is a trade-off in minimising lung pressure and potential damage, versus maximising recruitment. Recruitment is a function of PEEP and time [28,30]. Therefore, true minimal $E_{d r s}$ can only be determined after a stabilisation period is provided at each PEEP level. Such a process could be readily automated and monitored in a ventilator. Setting PEEP at minimum elastance theoretically benefits ventilation by maximising recruitment, reducing work of breathing and minimising overdistension $[12,14,15,34]$. The PIP can be seen to follow the $E_{d r s}$ trend to some extent. However, it does not provide the same degree of resolution. In some cases PIP is seen to stabilise quickly or remain relatively constant following a change in PEEP, while $E_{d r s}$ continues to change significantly indicating the occurrence of significant lung dynamics not readily apparent from monitoring airway pressure alone. This result shows the greater sensitivity of using $E_{d r s}$ and that $E_{d r s}$ captures more relevant dynamics than airway pressure alone.

\section{Oleic acid ARDS models \\ Subject 1}

The response of Subject 1 to PEEP titration is seen in Figure 1. The $E_{d r s}$ drops to an overall minimum at a PEEP of $15 \mathrm{cmH}_{2} \mathrm{O}$, suggesting that maintaining this level of PEEP provides the optimal trade-off between maximising recruitment and reducing the risk of lung damage [12].

\section{Subject 2}

The response of Subject 2 to PEEP titration is seen in Figure 2 and is similar to that of Subject 1 . However, the magnitude of the $E_{d r s}$ response to PEEP is reduced. The $E_{d r s}$ drops to an overall minimum at a PEEP of $15 \mathrm{cmH}_{2} \mathrm{O}$, implying optimal PEEP.

\section{Subject 3}

In Subject 3, $E_{d r s}$ rises to a maximum near the beginning of each breathing cycle before rapidly decreasing as seen in Figure 3. However, this trend is less pronounced at high PEEP levels. It is observed that Subject 3 had a more severe level of ARDS $\left(\mathrm{PaO}_{2} / \mathrm{FiO}_{2}=113.6 \mathrm{mmHg}\right)$ compared to Subject $1\left(\mathrm{PaO}_{2} / \mathrm{FiO}_{2}=126.6 \mathrm{mmHg}\right)$ or Subject $2\left(\mathrm{PaO}_{2} / \mathrm{FiO}_{2}=183.6 \mathrm{mmHg}\right)$, possibly resulting in the substantially different subject-specific response to PEEP titration. The airway pressure curves show an initial rapid increase followed by a more gradual increase. It is possible that a different flow profile may eliminate the initial rapid pressure increase and reduce the rise in $E_{d r s}$. The most uniform elastance across a breath occurs at a PEEP of $15 \mathrm{cmH}_{2} \mathrm{O}$ (at both increasing and decreasing PEEP), implying optimal PEEP.

\section{Lavage ARDS models Subject 4}

Respiratory elastance increases significantly in Subject 4 when PEEP is increased from 1 mbar to 5 mbar as seen in Figure 4. The lowest elastance is encountered either side of the RM at a PEEP of 1 mbar. However, $E_{d r s}$ reaches a local minimum at a PEEP of 15 mbar during decreasing PEEP. Thus, in this case, minimal elastance would suggest that the subject should be ventilated at 1 mbar rather than 15 mbar. However, it is important to note that atelectasis occurs in ARDS patients [35], and clinically, ARDS patients should be ventilated at higher PEEP [1,36,37]. Thus, this $E_{d r s}$ map outlines a potential drawback of ventilation considering only minimum elastance. Clinicians should thus consider an alternate PEEP value when an unrealistically low PEEP is recommended by elastance.

\section{Subject 5}

The response of Subject 5 to PEEP titration is seen in Figure 5. The $E_{d r s}$ drops to an overall minimum at a PEEP of 10 mbar, implying optimal PEEP.

\section{Subject 6}

Unlike Subjects 4 and 5, the RM performed on Subject 6 was performed during an open chest surgery, thereby neglecting the effect of $E_{c w}$ in Equation 2 and effectively capturing $E_{\text {lung }}$ directly. It was found that more noise was present in this trial when compared to closed chest ventilation performed on Subjects 1-5. The noise present in this data indicates that the chest wall may provide some form of damping to high frequency physiological or mechanical effects. It was observed that minimum elastance occurs at a decreasing PEEP of $10 \mathrm{mbar}$, as shown in Figure 6.

\section{Limitations}

The single compartment lung model used to derive $E_{d r s}$ does not capture some specific physiological aspects, such as cardiogenic oscillations or regional differences in mechanical properties [21]. Furthermore, the effects of non-linear flow or variations in airway resistance during a breath are also neglected [21]. The determination of $E_{d r s}$ accommodates whatever resistance value is chosen, such that the model perfectly fits the available pressure data. Hence, the assumption of constant resistance throughout a breath significantly impacts on the trends of $E_{d r s}$. There is evidence to suggest that in some cases respiratory resistance can vary within a breath [23]. However, the effect of the resistive term is mathematically limited in its impact [17]. Since this 
analysis is predominantly based on the comparison of trends across PEEP values, where each subject is thus their own reference, the best validation is the ability to track clinically expected trends as shown here.

It is important to note that both ARDS animal models were different in many aspects and do not allow for a statistically significant comparison. More importantly, it was not able to fully justify PEEP optimisation based solely on minimal elastance. However, the main outcome of this research is that mapping of time-varying respiratory elastance of mechanically ventilated ARDS subjects can be monitored to provide a high resolution metric to describe disease state and physiological changes in response to PEEP. This outcome shows the robustness of both the model and the method of visualisation for application in the ICU. However, more inter-patient variability is present in patients admitted to the ICU. Thus, application of this monitoring technique warrants further investigation in both human and animal studies.

Selecting patient-specific optimal PEEP remains widely debatable with little consensus [36,37]. This study primarily provides a means to visualise respiratory system elastance continuously, thus allowing PEEP to be titrated to minimal elastance $[12,14,15]$, and it was suggested that it can be done using either incremental or decremental phase of a staircase RM. However, this suggestion is limited to the protocol and data available. If only the incremental phase of the RM is available, PEEP titration can be performed during incremental stage, or vice-versa. If both incremental and decremental phase of the staircase RM are available, PEEP should be titrated during decreasing PEEP, as the incremental PEEP functions to recruit the collapsed lung $[38,39]$.

A further limitation is that the findings of this research are solely based on observation of the $E_{d r s}$ map. The findings require further investigation together with additional imaging and monitoring tools such as in-vivo microscopy, computer tomography and/or electrical impedance tomography for validation. However, high resolution imaging technology is currently limited to regional investigation and clinically impractical for full and continuous monitoring [40-42]. Thus, the findings of this research are limited to comparisons with existing literature.

\section{Conclusion}

Visualisation of the dynamic respiratory elastance provides significantly more insight into dynamic lung behaviour than can be provided by a single value of $E_{r s}$. Simultaneous monitoring of respiratory elastance across a breath and during a RM provides a new clinical perspective to guide therapy and provides unique subject-specific insight into the heterogeneous response to PEEP. The model is limited to a constant respiratory resistance throughout inspiration which may not be valid in some cases. However, trends match clinical expectation and the results highlight both the subject-specificity of the model, as well as significant inter-subject variability. Overall, further research is warranted to confirm the clinical potential of using this method in ARDS patients admitted to the ICU.

\section{Additional files}

\section{Additional file 1: Subject 1 - Oleic acid ARDS. Subject 2 - Oleic acid ARDS. Subject 3 - Oleic acid ARDS. Subject 4 - Lavage ARDS. \\ Subject 5 - Lavage ARDS. Subject 6 - Lavage ARDS. \\ Additional file 2: Top view of $E_{d r s}$ map for each subject.}

\section{Abbreviations}

ARDS: Acute respiratory distress syndrome; ICU: Intensive care unit; MV: Mechanical ventilation; PEEP: Positive end expiratory pressure; WOB: Work of breathing; PF: $\mathrm{PaO}_{2} / \mathrm{FiO}_{2}$; $\mathrm{ABG}$ : Arterial blood gas; RM: Recruitment manoeuvre; PIP: Peak inspiratory pressure.

\section{Competing interests}

The authors declare that they have no competing interests.

\section{Authors' contribution}

EJD assisted in the development of the $E_{d r s}$ model, generated the $E_{d r s}$ maps, and drafted the manuscript. YSC participated in the implementation of the clinical trials, assisted in the development of the $E_{\text {drs }}$ model, and helped to draft the manuscript. CP participated in the implementation of the clinical trials. GMS participated in the implementation and coordination of the study. $\mathrm{BL}$ and NJ participated in the implementation of the clinical trials. JGC participated in the implementation and coordination of the study, and helped to draft the manuscript. TD participated in the implementation and coordination of the study, implementation of the clinical trials, and helped to draft the manuscript. All authors read and approved the final manuscript.

\section{Acknowledgement}

The authors wish to thank Paul D. Docherty and members of mechanical ventilation research team in Center for Bio-Engineering, University of Canterbury and GIGA-Cardiovascular Sciences, University of Liege for supporting this work.

\section{Author details}

'University of Canterbury, Christchurch 8041, New Zealand. ${ }^{2}$ University of Liège, Liège, Belgium. ${ }^{3}$ Christchurch Hospital, Christchurch 8011, New Zealand. ${ }^{4}$ University Hospital of Liège, Liège, Belgium.

Received: 4 July 2013 Accepted: 19 February 2014

Published: 2 March 2014

\section{References}

1. The ARDS Definition Task Force A: Acute respiratory distress syndrome: the berlin definition. JAMA 2012, 307(23):2526-2533.

2. Gattinoni L, Pesenti A: The concept of "baby lung". Intensive Care Med 2005, 31(6):776-784.

3. Amato MBP, Barbas CSV, Medeiros DM, Magaldi RB, Schettino GP, Lorenzi-Filho G, Kairalla RA, Deheinzelin D, Munoz C, Oliveira R, Takagaki TY, Carvalho CRR: Effect of a protective-ventilation strategy on mortality in the acute respiratory distress syndrome. N Engl J Med 1998, 338(6):347-354.

4. The Acute Respiratory Distress Syndrome Network: Ventilation with lower tidal volumes as compared with traditional tidal volumes for acute lung injury and the acute respiratory distress syndrome. N Engl J Med 2000, 342(18):1301-1308.

5. McCann UG, Schiller HJ, Carney DE, Gatto LA, Steinberg JM, Nieman GF: Visual validation of the mechanical stabilizing effects of positive end-expiratory pressure at the alveolar level. J Surg Res 2001, 99(2):335-342. 
6. Halter JM, Steinberg JM, Schiller HJ, DaSilva M, Gatto LA, Landas S, Nieman GF: Positive End-expiratory pressure after a recruitment maneuver prevents both alveolar collapse and recruitment/derecruitment. Am J Respir Crit Care Med 2003, 167(12):1620-1626.

7. Gattinoni L, Carlesso E, Brazzi L, Caironi P: Positive end-expiratory pressure. Curr Opin Crit Care 2010, 16(1):39-44.

8. Lauzon AM, Bates JH: Estimation of time-varying respiratory mechanical parameters by recursive least squares. J App/ Physiol 1991 71(3):1159-1165

9. Sundaresan A, Yuta T, Hann CE, Geoffrey Chase J, Shaw GM: A minimal model of lung mechanics and model-based markers for optimizing ventilator treatment in ARDS patients. Comput Methods Programs Biomed 2009, 95(2):166-180.

10. Ma B, Bates J: Modeling the complex dynamics of derecruitment in the lung. Ann Biomed Eng 2010, 38(11):3466-3477.

11. Sundaresan A, Chase JG: Positive end expiratory pressure in patients with acute respiratory distress syndrome - The past, present and future. Biomed Signal Process Control 2011, 7(2):93-103.

12. Carvalho A, Jandre F, Pino A, Bozza F, Salluh J, Rodrigues R, Ascoli F, GiannellaNeto A: Positive end-expiratory pressure at minimal respiratory elastance represents the best compromise between mechanical stress and lung aeration in oleic acid induced lung injury. Crit Care 2007, 11(4):R86.

13. Lucangelo $U$, Bernabè $F$, Blanch L: Lung mechanics at the bedside: make it simple. Curr Opin Crit Care 2007, 13(1):64-72.

14. Suarez-Sipmann F, Bohm SH, Tusman G, Pesch T, Thamm O, Reissmann H, Reske A, Magnusson A, Hedenstierna G: Use of dynamic compliance for open lung positive end-expiratory pressure titration in an experimental study. Crit Care Med 2007, 35:214-221.

15. Lambermont B, Ghuysen A, Janssen N, Morimont P, Hartstein G, Gerard P, D'Orio V: Comparison of functional residual capacity and static compliance of the respiratory system during a positive end-expiratory pressure (PEEP) ramp procedure in an experimental model of acute respiratory distress syndrome. Crit Care 2008, 12(4):R91.

16. Brochard L, Martin G, Blanch L, Pelosi P, Belda FJ, Jubran A, Gattinoni L, Mancebo J, Ranieri VM, Richard J-C, Gommers D, Vieillard-Baron A, Pesenti A, Jaber S, Stenqvist O, Vincent J-L: Clinical review: Respiratory monitoring in the ICU - a consensus of 16. Crit Care 2012, 16(2):219.

17. Chiew YS, Chase JG, Shaw G, Sundaresan A, Desaive T: Model-based PEEP optimisation in mechanical ventilation. Biomed Eng Online 2011, 10(1):111

18. Zhao Z, Guttmann J, Moller K: Adaptive Slice Method: a new method to determine volume dependent dynamic respiratory system mechanics. Physiol Meas 2012, 33(1):51-64.

19. Schranz C, Becher T, Schadler D, Weiler N, Moeller K: Model-based ventialtor settings in pressure controlled ventilation. In Congress for the German Swiss and Austrian Society for Biomedical Engineering (BMT2013). Graz, Austria: Springer; 2013.

20. Esquinas Rodriguez A, Papadakos P, Carron M, Cosentini R, Chiumello D: Clinical review: helmet and non-invasive mechanical ventilation in critically ill patients. Crit Care 2013, 17(2):223.

21. Bates JHT: Lung Mechanics: an inverse modeling approach. United States of America, New York: Cambridge University Press; 2009.

22. Hann CE, Chase JG, Lin J, Lotz T, Doran CV, Shaw GM: Integral-based parameter identification for long-term dynamic verification of a glucose-insulin system model. Comput Methods Programs Biomed 2005, 77(3):259-270

23. Mols G, Kessler V, Benzing A, Lichtwarck-Aschoff M, Geiger K, Guttmann J: Is pulmonary resistance constant, within the range of tidal volume ventilation, in patients with ARDS? Br J Anaesth 2001, 86(2):176-182.

24. Chiew YS, Chase JG, Lambermont B, Janssen N, Schranz C, Moeller K, Shaw $G$, Desaive T: Physiological relevance and performance of a minimal lung model - an experimental study in healthy and acute respiratory distress syndrome model piglets. BMC Pulmonary Medicine 2012, 12(1):59.

25. Ballard-Croft C, Wang D, Sumpter LR, Zhou X, Zwischenberger JB: Large-animal models of acute respiratory distress syndrome. Ann Thorac Surg 2012, 93(4):1331-1339.

26. Hodgson CL, Tuxen DV, Bailey MJ, Holland AE, Keating JL, Pilcher D, Thomson KR, Varma D: A positive response to a recruitment maneuver with PEEP titration in patients with ARDS, regardless of transient oxygen desaturation during the maneuver. J Intensive Care Med 2011, 26(1):41-49.

27. Bates JHT, Irvin CG: Time dependence of recruitment and derecruitment in the lung: a theoretical model. J App/ Physio/ 2002, 93(2):705-713.
28. Albert SP, DiRocco J, Allen GB, Bates JHT, Lafollette R, Kubiak BD, Fischer J, Maroney S, Nieman GF: The role of time and pressure on alveolar recruitment. J Appl Physiol 2009, 106(3):757-765

29. Pelosi P, Goldner M, McKibben A, Adams A, Eccher G, Caironi P, Losappio S, Gattinoni L, Marini JJ: Recruitment and derecruitment during acute respiratory failure: an experimental study. Am J Respir Crit Care Med 2001, 164:122-130.

30. Barbas CSV, de Matos GFJ, Pincelli MP, da Rosa Borges E, Antunes T, de Barros JM, Okamoto V, Borges JB, Amato MBP, Ribeiro de Carvalho CR: Mechanical ventilation in acute respiratory failure: recruitment and high positive end-expiratory pressure are necessary. Curr Opin Crit Care 2005, 11(1):18-28

31. Ganzert S, Moller K, Steinmann D, Schumann S, Guttmann J: Pressure-dependent stress relaxation in acute respiratory distress syndrome and healthy lungs: an investigation based on a viscoelastic model. Crit Care 2009, 13(6):R199.

32. Andreassen S, Steimle KL, Mogensen ML, Serna JB, Rees S, Karbing DS: The effect of tissue elastic properties and surfactant on alveolar stability. J Appl Physiol 2010, 109(5):1369-1377.

33. Crotti S, Mascheroni D, Caironi P, Pelosi P, Ronzoni G, Mondino M, Marini JJ, Gattinoni L: Recruitment and derecruitment during acute respiratory failure. A clinical study. Am J Respir Crit Care Med 2001, 164(1):131-140.

34. Zhao Z, Steinmann D, Frerichs I, Guttmann J, Moller K: PEEP titration guided by ventilation homogeneity: a feasibility study using electrical impedance tomography. Crit Care 2010, 14:R8.

35. Hedenstierna G, Rothen HU: Atelectasis formation during anesthesia: causes and measures to prevent it. J Clin Monit Comput 2000, 16:329-335.

36. Briel M, Meade M, Mercat A, Brower RG, Talmor D, Walter SD, Slutsky AS, Pullenayegum E, Zhou Q, Cook D, Brochard L, Richard J-CM, Lamontagne F, Bhatnagar N, Stewart TE, Guyatt G: Higher vs lower positive end-expiratory pressure in patients with acute lung injury and acute respiratory distress syndrome: Systematic review and meta-analysis. JAMA 2010, 303(9):865-873.

37. Mercat A, Richard J-CM, Vielle B, Jaber S, Osman D, Diehl J-L, Lefrant J-Y, Prat G, Richecoeur J, Nieszkowska A, Gervais C, Baudot J, Bouadma L, Brochard L, Expiratory Pressure Study Group (Express): Positive end-expiratory pressure setting in adults with acute lung injury and acute respiratory distress syndrome: a randomized controlled trial. JAMA 2008, 299(6):646-655.

38. Huh J, Jung H, Choi H, Hong S-B, Lim C-M, Koh Y: Efficacy of positive end-expiratory pressure titration after the alveolar recruitment manoeuvre in patients with acute respiratory distress syndrome. Crit Care 2009, 13(1):R22.

39. Suarez-Sipmann F, Bohm S: Recruit the lung before titrating the right positive end-expiratory pressure to protect it. Crit Care 2009, 13(3):134

40. Malbouisson LM, Muller J-C, Constantin J-M, Lu QIN, Puybasset L, Rouby J-J, the CTSASG: Computed tomography assessment of positive end-expiratory pressure-induced alveolar recruitment in patients with acute respiratory distress syndrome. Am J Respir Crit Care Med 2001, 163(6):1444-1450.

41. Zhao Z, Steinmann D, Muller-Zivkovic D, Martin J, Frerichs I, Guttmann J, Moller K: A lung area estimation method for analysis of ventilation inhomogeneity based on electrical impedance tomography. J Xray Sci Technol 2010, 18:171-182.

42. Zhao Z, Moller K, Steinmann D, Frerichs I, Guttmann J: Evaluation of an electrical impedance tomography-based global inhomogeneity index for pulmonary ventilation distribution. Intensive Care Med 2009, 35:1900-1906.

doi:10.1186/1471-2466-14-33

Cite this article as: van Drunen et al:: Visualisation of time-varying respiratory system elastance in experimental ARDS animal models. BMC Pulmonary Medicine 2014 14:33. 